\title{
BCFA-enriched vernix-monoacylglycerol reduces LPS-induced inflammatory markers in human enterocytes in vitro
}

\author{
Yuanyuan Yan ${ }^{1}$, Zhen Wang ${ }^{2}$, Donghao Wang ${ }^{2}$, Peter Lawrence ${ }^{2}$, Xingguo Wang ${ }^{1}$, Kumar S.D. Kothapalli ${ }^{3}$, \\ Jacelyn Greenwald ${ }^{2}$, Ruijie Liu', Hui Gyu Park ${ }^{3}$ and J. Thomas Brenna ${ }^{3}$
}

BACKGROUND: Excess vernix caseosa produced by the fetal skin appears as particles suspended in the amniotic fluid in late gestation, is swallowed by the fetus, and is found throughout the newborn gastrointestinal tract as the first organisms are arriving to colonize the gut. Lipid-rich vernix contains an unusually high $29 \%$ branched chain fatty acids (BCFA). BCFAs reduce the incidence of necrotizing enterocolitis in an animal model, and were recently found predominantly in the sn-2 position of human milk triacylglycerols. Nothing is known about the influence of vernix BCFA on proinflammatory markers in human enterocytes.

METHODS: We investigated the effect of vernixmonoacylglycerides (MAGs) (enriched with 30\% BCFA) on interleukin (IL)-8 and NF-KB production in a human intestinal epithelial cell line (Caco-2). Caco-2 cells were pretreated with vernix-MAG or vernix-free fatty acid (FFA) prior to lipopolysaccharide (LPS) activation.

RESULTS: Both vernix-MAG and vernix-FFA increased cell BCFA and eliminated an LPS-induced 20\% reduction in cell viability. In stimulated Caco-2 cells, vernix-MAG was more effective than vernix-FFA in suppressing $I L-8$ and NF-KB. Activated vernix-MAG-treated cells expressed less of the cell-surface Toll-like receptor4 (TLR-4) compared with controls. CONCLUSION: This is the first study to show the reduction of proinflammatory markers in human cells mediated by BCFA-MAG.

$\mathbf{V}$ ernix caseosa is a lipid-laden film formed on the fetal surface during the last trimester of pregnancy. It is composed mainly of water (80.5\%), lipids (10.3\%), and proteins $(9.1 \%)(1)$. The lipids are derived from the stratum corneum and sebaceous glands and appear primarily as sterol esters (25-30\%), triacylglycerols (TAG) (18-36\%), wax esters (12-16\%), squalene (9\%), and ceramides (5\%) (2-4). Branched chain fatty acids (BCFAs) are present in all acylcarrying lipid classes, wax esters (where they are $16-53 \%$ of fatty acids), sterol esters (27-62\%) (2-5), TAG (18-21\%), and nonesterified fatty acids (21\%) (3).
The high concentration of BCFA led us to propose that vernix is important for development of the gastrointestinal tract (6). The anti-inflammatory effects of some fatty acids are well known from studies dating to the 1970s on cardiovascular disease and many other conditions. The long-chain polyunsaturated fatty acids (LCPUFA), docosahexaenoic acid (DHA, 22:6(n-3)), and eicosapentaenoic acid (EPA, 20:5(n3)), are best studied for the anti-inflammatory and proresolving properties of their eicosanoid and docosanoid products (7-9). Fatty acids in their monoacylglyceride (MAG) form are incorporated into mixed micelles for normal fat absorption. MAGs are a GRAS (generally recognized as safe) ingredient for food applications. MAG containing PUFA have antiinflammatory properties in vitro $(10,11)$, and lymphatic absorption of DHAs given as MAG and DAG (diacylglycerides) is more effective than as DHA, TAG, and EE (ethyl esters) in rats (12). Moreover, BCFA in the form of sn-2 MAG incorporated more effectively into human intestinal cells compared with that of free fatty acids (13).

In our previous research, BCFAs were found to downregulate proinflammatory cytokine IL-8 mRNA and the downstream signaling NF- $\mathrm{\kappa B}$ in human LPS-stimulated cells preincubated with BCFA (14). Oral administration of lipids simulating BCFA-rich vernix (BCFA is $20 \% \mathrm{w} / \mathrm{w}$ of total fatty acids) reduced the incidence of necrotizing enterocolitis (NEC) in rat pups compared with a non-BCFA-feeding group (6). No data are available on the inflammatory properties of BCFA-MAG compared with BCFA-FFA (free fatty acid). Here we compared the physiological activity of MAG enriched with 20\% BCFA derived from vernix TAG, from the perspective of inflammation markers, with that of the free fatty acid form which shares the same FA profile.

\section{METHODS}

The collection of vernix caseosa for research was reviewed and approved by the Cornell University and the Cayuga Medical Center Institutional Review Boards (IRB) on the use of human subjects. The IRBs approved an exemption from the requirement to obtain individual informed consent because vernix is deemed to be medical waste and no individually identifiable information was obtained from participants.

\footnotetext{
${ }^{1}$ Collaborative Innovation Center of Food Safety and Quality Control in Jiangsu Province, National Engineering Research Center for Functional Food, School of Food Science and Technology, Jiangnan University, Wuxi, China; ${ }^{2}$ Division of Nutritional Sciences, Cornell University, Ithaca, New York; ${ }^{3}$ Department of Pediatrics, Dell Pediatric Research Institute, Dell Medical School, University of Texas at Austin, Austin, Texas. Correspondence: J. Thomas Brenna (tbrenna@utexas.edu) 


\section{Sample Collection}

Twenty vernix samples from 20 normal term newborns were collected from Cayuga Medical Center (Ithaca, NY). Vernix removed from the shoulder regions in the birthing room was stored in clean tubes at $-80^{\circ} \mathrm{C}$ until analysis.

\section{Preparation of sn-2 MAG from Vernix Lipid}

Total lipids from a pool of vernix samples were extracted based on a modified Bligh and Dyer method (15). TAG was separated from total vernix lipids by thin-layer chromatography (TLC) using hexane:ethyl ether:formic acid $=80: 20: 1, \mathrm{v} / \mathrm{v} / \mathrm{v}$. The TAG spot was scraped and extracted.

Hydrolysis of TAG was based on a modification of the method described by Luddy et al. (16). Fifty milligrams of vernix TAG was mixed with $1 \mathrm{ml}$ of $1 \mathrm{M}$ Tris-HCl buffer ( $\mathrm{pH} 8.0$ ), $0.25 \mathrm{ml}$ of $0.05 \%$ bile salts, $0.1 \mathrm{ml}$ of $2.2 \% \mathrm{CaCl}_{2}$, and $15 \mathrm{mg}$ of pancreatic lipase (Sigma Product Number: L3126). After $3 \mathrm{~min}$ at $40^{\circ} \mathrm{C}$ with shaking every $30 \mathrm{~s}$ for $10 \mathrm{~s}$, lipids were extracted by ethyl ether. Sn-2 MAG was separated by TLC, and developed in hexane:ethyl ether:acetic acid $=50: 50: 1, \mathrm{v} / \mathrm{v} / \mathrm{v}$.

Free fatty acids were obtained from sn-2 MAG vernix by hydrolysis. In this way, sn-2 MAG and FFA share the same fatty acid profile.

\section{Cell Culture}

Caco-2 cells were cultured in Dulbecco's Modified Eagle's Medium (ThermoFisher Scientific, Waltham, MA) with $10 \%$ FBS and kept in a humidified environment at $37^{\circ} \mathrm{C}$ with $5 \% \mathrm{CO}_{2}$. The cell culture medium was changed every $2-3$ days. Cells were subcultured after reaching $80 \%$ confluence using a trypsin-EDTA solution.

\section{Fatty Acid Supplementation and Inflammatory Stimulus}

The average density of Caco- 2 cells was $1 \times 10^{6}$ cells per dish. Cells were preincubated with albumin-complexed sn- 2 vernix-MAG and FFA for $24 \mathrm{~h}$ at $25 \mu \mathrm{M}$ concentrations of total fatty acids. The cells were washed twice with $1 \times$ phosphate-buffered saline and then incubated with LPS at a final concentration of $5 \mu \mathrm{g} / \mathrm{ml}$ for $24 \mathrm{~h}$. Cells were washed twice with $1 \times$ PBS and harvested using trypsin.

\section{Cell Viability}

Cell viability was examined by the methylthiazole tetrazolium assay. After FFA or MAG incubation and subsequent LPS stimulation, cells were then incubated with 3-(4,5-dimethylthiazol-2-thiazoyl)-2,5diphenyl tetrazolium bromide $\left(1 \mathrm{mg} / \mathrm{ml}\right.$; Sigma) at $37^{\circ} \mathrm{C}$ for $3 \mathrm{~h}$. A microplate colorimeter (Bio-Rad, Hercules, CA) was used to read the amount of the formazan product at wavelength $570 / 690 \mathrm{~nm}$.

\section{Fatty Acid Extraction and Analysis}

Fatty acid methyl esters of harvested cell pellets were produced based on a modified one-step method (17). Gas chromatography electron ionization tandem mass spectrometry of the molecular ions was used to verify structures of the fatty acid component $(18,19)$. Quantitative analysis was performed by GC-flame ionization detection using an equal weight fatty acid methyl ester mixture (462A; Nu-Chek Prep, Elysian, $\mathrm{Mn}$ ) to determine response factors. The corrected peak areas were then normalized to C18:2n- 6 because it did not change between control and treatments. GC analyses were performed in triplicates.

\section{RNA Isolation and CDNA Synthesis}

Total RNA of Caco-2 cells was extracted using RNeasy Mini kit (Qiagen, Hilden, Germany) and was then quantified and purity-verified

Table 1. Primers sequence (annealing temperature $=58^{\circ} \mathrm{C}$ )

\begin{tabular}{lcc}
\hline Gene & Forward primer $5^{\prime}-3^{\prime}$ & Reverse primer $5^{\prime}-3^{\prime}$ \\
\hline IL-8 & CTTGGCAGCCTTCCTGATT & GGGTGGAAAGGTTGGAGTATG \\
NF-KB & CGTTTCCGTTATGTATGTGAAGG & CTITGCTGGTCCCACATAGT \\
TLR-4 & CCTAAGCCACCTCTCTACCTTA & AGCCACCAGCTTCTGTAAAC \\
\hline
\end{tabular}

using a NanoDrop 2000 (Thermo Fisher Scientific). One microgram of total RNA was reverse-transcribed into cDNA using the High-Capacity cDNA Reverse Transcription Kit (Life Technologies), which was used as the template for semiquantitative real-time PCR and quantitative realtime PCR (qRT-PCR) reactions.

\section{Semiquantitative and Quantitative RT-PCR}

Gene-specific primers (Table 1) were designed by Primer Quest software (Integrated DNA Technologies (IDT), Coralville, IA) and purchased from a single vendor IDT. Semiquantitative RT-PCR amplification reactions ran on a gradient thermal cycler (Eppendorf, Hamburg, Germany) using Emerald Amp GT PCR Master Mix (Clontech, Mountain View, CA). PCR products were separated on $2 \%$ agarose gel stained with ethidium bromide. The amplicon bands were checked using UV light. GAPDH and $\beta$-actin were used as housekeeping genes.

Quantitative RT-PCR transcript levels were analyzed using SYBR Green Master Mix (Roche, Madison, WI). The expression levels of IL-8 and NF- $\kappa$ B transcripts were measured on a Light Cycler 480 instrument (Roche), and the data were normalized using the geometric mean of reference control genes GAPDH and $\beta$-actin. All reactions were run in triplicates. The thermal cycling conditions of initial denaturation were as follows: $95^{\circ} \mathrm{C}$ for $10 \mathrm{~min}$ followed by 45 cycles of $95^{\circ} \mathrm{C}$ for $10 \mathrm{~s}, 65^{\circ} \mathrm{C}$ for $20 \mathrm{~s}, 72^{\circ} \mathrm{C}$ for $10 \mathrm{~s}$, and a final extension at $72^{\circ} \mathrm{C}$ for $10 \mathrm{~min}$. The $2^{-\Delta \Delta} \mathrm{CT}$ method was used to perform relative quantification.

\section{Chemicals}

Solvents for lipid extraction were HPLC grade from Sigma-Aldrich (St. Louis, MO) and Burdick \& Jackson (Muskegon, MI). Media, FBS, and reagents for cell culture were acquired from Corning, Inc. (Corning, NY), and Thermo Fisher Scientific.

\section{Statistics}

Data are presented as mean \pm standard deviation of at least two biological replicates and twice of each experiment. Statistical evaluation was accomplished using IBM SPSS (Version 23). Differences in the mean of gene expression were calculated using one-way ANOVA and when significant $(P<0.05)$, followed a post hoc test, also $P<0.05$ was considered significant.

\section{RESULTS}

Effect of sn-2 MAG and FFA from Vernix TAG on the Viability of Caco-2 Cells with LPS Stimulation

Caco-2 cell viabilities were investigated quantitatively by methylthiazole tetrazolium assays, presented in Figure 1. The viability of LPS-stimulated cells decreased by $\sim 20 \%$ compared with normal Caco- 2 cells. When cells were pretreated with vernix lipids before LPS incubation, cell viability returned to the value found for the unstimulated cells.

\section{Uptake of BCFA in sn-2 MAG and FFA from Vernix TAG by Caco- 2 Cells}

The fatty acid composition of sn-2 MAG from vernix TAG is presented in Table 2. BCFA constituted $33.93 \pm 0.21 \%$, $\mathrm{wt} / \mathrm{wt}$ of all FA in vernix-MAG derived from vernix TAG. In total, 13 of the $35 \mathrm{FA}$ identified in vernix-MAG were BCFA. Vernix-MAG BCFA ranged from 13 to 21 carbon atoms.

BCFAs are a significant component of vernix lipids. Caco-2 cells readily take up BCFA from vernix-MAG and FFA after treatment $(25 \mu \mathrm{M})$, as presented in Table 3. Vernix-MAG and FFA treatment caused an increase in cell iso-14:0, iso-15:0, anteiso-15:0, and iso-16:0. Sn-2 MAG BCFA treatment led to 


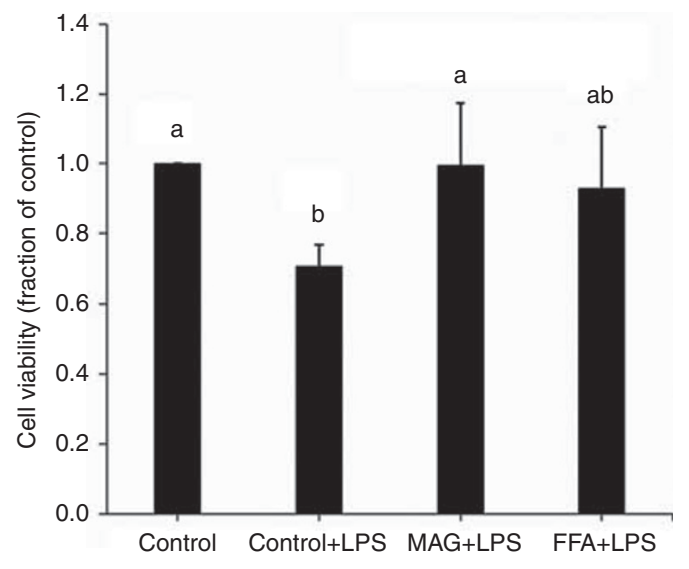

Figure 1. Cell viability before and after treatment compared with inflammatory control. Vernix-MAG or vernix-FFA were individually incubated at $25 \mu \mathrm{M}$ concentrations. The number of replicates in any group was five. Error bars represent standard deviations. Different letters indicate significant differences, $P<0.05$. FFA, free fatty acid; MAG, monoacylglyceride.

higher accumulation of BCFA (iso-14:0, iso-15:0, anteiso-15:0, iso-16:0, anteiso-17:0, and iso-18:0) than that of BCFA as FFA. The sum of BCFA was significantly higher in cells incubated with vernix-MAG than those incubated with FFA. Our findings indicate that both vernix-MAG and FFA are readily uptaken by Caco- 2 cells with sn-2 MAG more efficacious.

Effect of sn-2 MAG and FFA from Vernix TAG on Interleukin-8 Gene Expression

To investigate the impact of the structure of lipids on proinflammatory mediators, we pretreated cells with vernixMAG or FFA containing 20\% BCFA, derived from vernix TAG, and then stimulated the cells with LPS $(5 \mu \mathrm{g} / \mathrm{ml})$ and measured proinflammatory mediator expression. Q-PCR results of IL-8 expression are shown in Figure 2a. Compared with untreated cells, IL-8 expression significantly increased in LPS-stimulated cells. In contrast, cells preincubated with vernix-MAG and FFA show significantly decreased expression of IL-8 upon stimulation relative to controlstimulated cells. Among the two vernix-treated cells, IL-8 expression of vernix-MAG-treated cells was significantly lower than that of vernix-FFA cells.

\section{Effect of sn-2 MAG and FFA from Vernix TAG on NF-KB Gene Expression}

NF- $\kappa B$ expression was significantly increased in LPSstimulated Caco-2 cells (Figure 2b). Both MAG and FFA from vernix TAG suppressed LPS-induced NF- $\mathrm{\kappa B}$ expression. Vernix-MAG decreased NF- $\mathrm{KB}$ expression by an estimated $40 \%$ of the mean unstimulated controls, whereas vernix-FFA reduced expression by only $20 \%$. These findings suggest that vernix lipid treatment attenuates inflammation by decreasing NF- $\kappa \mathrm{B}$ expression, and that MAG does so more successfully than FFA.
Table 2. Sn-2 MAG (from vernix TAG) fatty acid profile (\%, wt/wt)

\begin{tabular}{|c|c|}
\hline$\% \mathrm{FA}$ & Mean \pm SD \\
\hline iso-12:0 & $0.30 \pm 0.03$ \\
\hline $12: 0$ & $0.16 \pm 0.01$ \\
\hline iso-13:0 & $0.12 \pm 0.01$ \\
\hline anteiso-13:0 & $0.20 \pm 0.02$ \\
\hline 13:0 & $0.46 \pm 0.02$ \\
\hline iso- $14: 0$ & $3.82 \pm 0.04$ \\
\hline $14: 0$ & $6.31 \pm 0.08$ \\
\hline $14: 1$ & $1.67 \pm 0.02$ \\
\hline iso-15:0 & $1.48 \pm 0.00$ \\
\hline anteiso-15:0 & $2.67 \pm 0.02$ \\
\hline 15:0 & $9.27 \pm 0.14$ \\
\hline 15:1 & $1.36 \pm 0.03$ \\
\hline iso- $16: 0$ & $3.23 \pm 0.02$ \\
\hline $16: 0$ & $39.09 \pm 0.22$ \\
\hline $16: 1 n-10$ & $6.47 \pm 0.21$ \\
\hline $16: 1 n-7$ & $1.78 \pm 0.16$ \\
\hline $16: 1 n-5$ & $0.46 \pm 0.04$ \\
\hline anteiso-17:0 & $0.64 \pm 0.03$ \\
\hline $17: 0$ & $2.55 \pm 0.03$ \\
\hline 12,14-dimethyl16:0 & $0.10 \pm 0.00$ \\
\hline 17:1 & $1.15 \pm 0.03$ \\
\hline iso-18:0 & $0.25 \pm 0.14$ \\
\hline 18:0 & $3.63 \pm 0.02$ \\
\hline 18:1n-9 & $4.02 \pm 0.01$ \\
\hline 18:1n-7 & $0.46 \pm 0.02$ \\
\hline 19:0 & $0.08 \pm 0.02$ \\
\hline $18: 2 n-6$ & $0.22 \pm 0.05$ \\
\hline iso-20:0 & $2.73 \pm 0.12$ \\
\hline $20: 0$ & $1.18 \pm 0.02$ \\
\hline 20:1n-9 & $0.44 \pm 0.00$ \\
\hline $20: 1 n-7$ & $0.39 \pm 0.03$ \\
\hline anteiso-21:0 & $0.38 \pm 0.06$ \\
\hline $21: 0$ & $0.09 \pm 0.01$ \\
\hline iso- $22: 0$ & $1.94 \pm 0.01$ \\
\hline $22: 0$ & $0.88 \pm 0.05$ \\
\hline BCFA & $33.93 \pm 0.21$ \\
\hline
\end{tabular}

FA, fatty acid; MAG, monoacylglyceride; TAG, triacylglycerols.

Effect of sn-2 MAG and FFA from Vernix TAG on TLR-4 Gene Expression

We investigated the differences of sn-2 MAG and FFA from vernix TAG on expression levels of TLR-4. Q-PCR of TLR-4 cells was not possible in unstimulated Caco-2 cells due to the low mRNA abundance. TLR-4 expression was then tested by semiquantitative RT-PCR using agarose gel electrophoresis. Figure 3 shows that TLR-4 expression varied based on lipid structure. LPS induced an increase in TLR-4 expression 
Table 3. Vernix BCFA uptake by Caco-2 cells (mean \pm SD, normalized to $(18: 2 n-6)$

\begin{tabular}{lcccc}
\hline BCFA & Control & Control+LPS & $\begin{array}{c}\text { Vernix sn-2 } \\
\text { MAG+LPS }\end{array}$ & $\begin{array}{c}\text { Vernix sn-2 } \\
\text { MAG FFA+LPS }\end{array}$ \\
\hline iso-14:0 & $0.01 \pm 0.00 \mathrm{a}$ & $0.02 \pm 0.01 \mathrm{a}$ & $0.17 \pm 0.01 \mathrm{c}$ & $0.07 \pm 0.01 \mathrm{~b}^{\mathrm{a}}$ \\
iso-15:0 & $0.07 \pm 0.02 \mathrm{a}$ & $0.07 \pm 0.01 \mathrm{a}$ & $0.16 \pm 0.02 \mathrm{~b}$ & $0.14 \pm 0.04 \mathrm{~b}$ \\
$\begin{array}{l}\text { anteiso- } \\
\text { 15:0 }\end{array}$ & $0.06 \pm 0.01 \mathrm{a}$ & $0.05 \pm 0.02 \mathrm{a}$ & $0.16 \pm 0.03 \mathrm{c}$ & $0.09 \pm 0.00 \mathrm{ab}$ \\
iso-16:0 & $0.02 \pm 0.02 \mathrm{a}$ & $0.05 \pm 0.01 \mathrm{a}$ & $0.33 \pm 0.03 \mathrm{c}$ & $0.11 \pm 0.01 \mathrm{~b}$ \\
anteiso- & $0.13 \pm 0.02 \mathrm{a}$ & $0.09 \pm 0.02 \mathrm{~b}$ & $0.13 \pm 0.03 \mathrm{a}$ & $0.09 \pm 0.02 \mathrm{~b}$ \\
17:0 & & & & \\
iso-18:0 & $0.11 \pm 0.03 \mathrm{ab}$ & $0.10 \pm 0.01 \mathrm{~b}$ & $0.15 \pm 0.04 \mathrm{a}$ & $0.10 \pm 0.01 \mathrm{~b}$ \\
iso-20:0 & $0.10 \pm 0.02 \mathrm{a}$ & $0.05 \pm 0.01 \mathrm{~b}$ & $0.06 \pm 0.04 \mathrm{ab}$ & $0.05 \pm 0.02 \mathrm{~b}$ \\
BCFA & $0.51 \pm 0.12 \mathrm{a}$ & $0.42 \pm 0.09 \mathrm{a}$ & $1.15 \pm 0.20 \mathrm{~b}$ & $0.64 \pm 0.11 \mathrm{a}$ \\
\hline
\end{tabular}

BCFA, branched chain fatty acid; FFA, free fatty acid; MAG, monoacylglyceride; LPS, lipopolysaccharide.

${ }^{a}$ Different letters indicate significant differences, $P<0.05$.
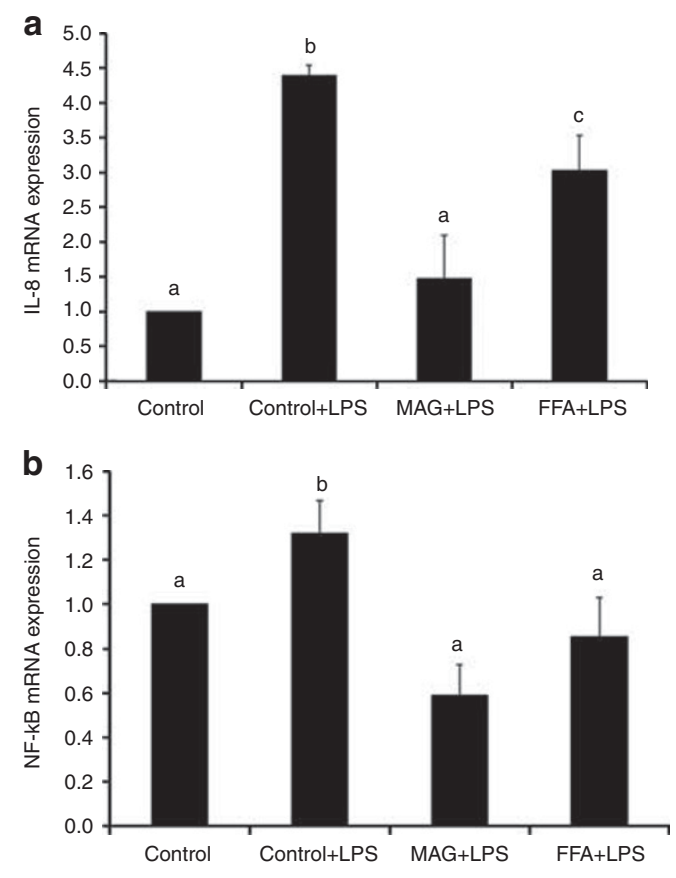

Figure 2. Key inflammatory gene expression in Caco-2 cells after LPS stimulation. Vernix-MAG or vernix-FFA were individually incubated at $25 \mu \mathrm{M}$ concentrations. Expression was measured by RT-PCR and normalized to $\beta$-actin and GAPDH. Means \pm SE $(n=3)$. Different letters indicate significant differences, $P<0.05$. (a) IL-8 expression induced by LPS is attenuated by BCFA. Vernix-MAG returns IL-8 to control levels and is more effective than FFA. (b) NF-KB expression is attenuated with both MAG and FFA. BCFA, branched chain fatty acid; FFA, free fatty acid; MAG, monoacylglyceride; LPS, lipopolysaccharide.

compared with normal Caco-2 cells. When compared with control cells and vernix-FFA-treated cells, both stimulated with LPS, MAG- treated cells with the same LPS stimulation had lower TLR-4 expression (Figure 3).

\section{DISCUSSION}

Lipolysis in newborn premature infants begins immediately upon ingestion when acid-stable lingual lipase secreted from

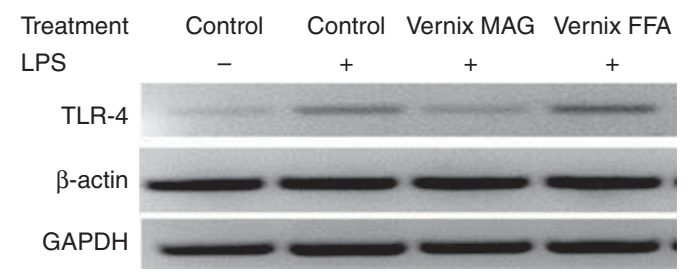

Figure 3. TLR-4 expression in Caco-2 cells after LPS stimulation. VernixMAG or vernix-FFA were individually incubated at $25 \mu \mathrm{m}$ concentrations. Representative image of agarose gel electrophoresis of TLR-4 RT-PCR products compared with housekeeping $\beta$-actin and GAPDH controls. FFA, free fatty acid; MAG, monoacylglyceride; LPS, lipopolysaccharide; TLR-4, Toll-like receptor4.

the tongue accompanies fat to the stomach. Gastric and lingual lipases hydrolyze more than $30 \%$ of TAG within several minutes to yield FFA and 2-MAG (20). While no specific analyses have been done on the gestating fetus, results on newborn premature infants strongly suggest that this process is active in utero $(21,22)$. It is reasonable to hypothesize that the predominant form of lipids entering the fetal gastrointestinal tract is FFA and 2-MAG, similar to newborns and normally in all life stages. Further, because vernix caseosa is unique to humans among land mammals, it is likely that the human fetal gastrointestinal tract is unique in its handling high levels of BCFA-rich lipids. For this reason, human fetal enterocytes may well have metabolism specific to unique components of vernix, specifically BCFA in the sn-2 position of MAG, among others.

Fatty acids and 2-MAG absorbed into enterocytes are resynthesized into triacylglycerols, and then assembled into chylomicrons and secreted into lymph. Nascent chylomicron triacylglycerols retain the TAG sn-2 fatty acid of the ingested TAG (23), strongly suggesting that the original sn-2 MAG is transported intact from intestinal lumen to bloodstream, whereas the fatty acids in the sn- 1 and sn-3 positions are available to the cell's FFA pool and are scrambled upon reesterification (24). Therefore, in the enterocyte, FFA and sn2 MAG may have different fates prior to resynthesis of TAG, for instance, preferential incorporation into membrane phospholipids (6). We have previously shown that sn-2 MAG BCFA are incorporated into Caco-2 phospholipids more readily than FFA BCFA, suggesting one explanation why human milk BCFA are predominantly in the sn-2 position of TAG (13).

Enterocytes turn over rapidly at all life stages, according to some balance of apoptosis/necrosis and cell proliferation. An important regulatory function required for maintenance of function is the ability to maintain the epithelial barrier function while enabling increased proliferation upon accelerated cell death due to an insult (25). Preincubation of MAG and FFA from vernix TAG suppressed the LPS stimulation, which induced a decrease in cell viability. It is tempting to draw a parallel to the case of the very premature infant born before 27 weeks of gestation, prior to the time when vernix caseosa enters the amniotic fluid in appreciable amounts. Our control cells simulate this situation because there is no 


\section{Articles | Yan et al.}

exposure to vernix BCFA of any type. The premature gut with Gram-negative pathogens may be especially vulnerable to a breach of the barrier and necrosis, similar to NEC. When BCFA was provided in feeds as $20 \% \mathrm{w} / \mathrm{w}$ of FA simulating BCFA levels found in vernix, neonatal rats had a $50 \%$ reduction of the incidence of NEC and an enhancement of anti-inflammatory IL-10 in vivo by threefold. Interestingly, the often deadly pathogen Pseudomonas aeruginosa increased several fold in the healthier, BCFA-treated group (6), supported by in vitro measurements showing that BCFA reduce motility and presumably virulence. In total, these studies suggest a protective role for vernix lipids.

In a separate study, vernix from newborn human infants was complexed with pulmonary surfactant into liposomes and introduced into the amniotic fluid of pregnant rabbits. The liposomes were absorbed and were protective against damage from surgery (26). The present data suggest that the mechanism may at least in part be due to an antiinflammatory action of vernix BCFA.

The fatty acid profile of Caco-2 cells after treatment revealed a significant increase in shorter-chain BCFA (iso14:0, iso-15:0, anteiso-15:0, and iso-16:0) compared with the level found in control cells. Of note, no significant difference was found in longer-chain BCFA (anteiso-17:0, iso-18:0, and iso-20:0) levels between vernix lipid treatment and control. We recently reported that shorter-chain BCFA have higher incorporation efficiency in $\mathrm{H} 4$ human fetal cells compared with longer-chain BCFA, and our present results show the same pattern (14). When Caco-2 cells were treated with individual BCFA, shorter-chain BCFA were preferentially incorporated into cells than longer-chain BCFA (14). The relatively greater level of shorter chain may at least in part explain why, when supplied at the same concentration, shorter-chain BCFA more effectively reduce inflammatory biomarkers than longer-chain BCFA. Moreover, BCFA as 2MAG appeared at greater levels than FFA in cells. This finding was similar to the situation with PUFA MAG which increased incorporation of omega-3 fatty acids in vivo $(27,28)$.

The majority of proinflammatory mediators are regulated at the transcription level (29), with NF- $\kappa \mathrm{B}$ being the main transcription factor involved in upregulation of proinflammatory cytokines (30). TLR-4 is involved in LPS signaling and serves as a cell-surface co-receptor for CD14, leading to LPS-mediated NF-kB activation and subsequent cellular events (31). We investigated the possible anti-inflammatory activity of sn-2 MAG and FFA from vernix TAG by analyzing the expression of proinflammatory mediator IL-8 and transcription factor NF- $\kappa \mathrm{B}$, and the membrane receptor TLR- 4 in LPS-stimulated cells. Sn-2 MAG and FFA from vernix TAG reduced LPS-induced production of IL-8, NF- $\kappa \mathrm{B}$, and TLR-4. This means sn-2 MAG and FFA from vernix TAG appeared to attenuate inflammatory activity in LPS-stimulated human intestinal cells. However, the pattern of mRNA NF-kB expression does not accurately match that of TLR-4. A possible reason for this is that IL-8 production in LPS-stimulated Caco-2 cells is not regulated by TLR-4/NF-kB alone.
In conclusion, treatment of sn-2 MAG or FFA derived from vernix TAG decreased the expression of LPS-induced proinflammatory mediator IL- 8 and NF- $\kappa B$ in human intestinal cells. These results are consistent with reduced intestinal inflammation in BCFA-treated neonatal rats. BCFA-MAG derived from vernix may be a key modulating factor in prevention of inflammation, and may well have activities in inflammatory conditions in later life.

\section{STATEMENT OF FINANCIAL SUPPORT}

This work was supported by grants from the Chinese Scholarship Council (to Y.Y.).

Disclosure: The authors declare no conflict of interest.

\section{REFERENCES}

1. Hoeger P, Schreiner V, Klaassen I, Enzmann C, Friedrichs K, Bleck O. Epidermal barrier lipids in human vernix caseosa: corresponding ceramide pattern in vernix and fetal skin. Br J Dermatol 2002;146: 194-201.

2. Nicolaides N, Fu HC, Ansari M, Rice GR. The fatty acids of wax esters and sterol esters from vernix caseosa and from human skin surface lipid. Lipids 1972;7:506-17.

3. Rissmann R, Groenink HW, Weerheim AM, Hoath SB, Ponec M, Bouwstra JA. New insights into ultrastructure, lipid composition and organization of vernix caseosa. J Invest Dermatol 2006;126:1823-33.

4. Kaerkkaeinen J, Nikkari T, Ruponen S, Haahti E. Lipids of vernix caseosa. J Invest Dermatol 1965;44:333-8.

5. Nazzaro-Porro M, Passi S, Boniforti L, Belsito F. Effects of aging on fatty acids in skin surface lipids. J Invest Dermatol 1979;73:112-7.

6. Ran-Ressler RR, Khailova L, Arganbright KM, et al. Branched chain fatty acids reduce the incidence of necrotizing enterocolitis and alter gastrointestinal microbial ecology in a neonatal rat model. PLoS ONE 2011;6:e29032.

7. Chen W, Esselman WJ, Jump DB, Busik JV. Anti-inflammatory effect of docosahexaenoic acid on cytokine-induced adhesion molecule expression in human retinal vascular endothelial cells. Invest Ophthalmol Vis Sci 2005;46:4342-7.

8. Marion-Letellier R, Butler M, Déchelotte P, Playford RJ, Ghosh S. Comparison of cytokine modulation by natural peroxisome proliferatoractivated receptor $\gamma$ ligands with synthetic ligands in intestinal-like Caco2 cells and human dendritic cells-potential for dietary modulation of peroxisome proliferator-activated receptor $\gamma$ in intestinal inflammation. Am J Clin Nutr 2008;87:939-48.

9. De Caterina R, Cybulsky MI, Clinton SK, Gimbrone MA, Libby P. The omega-3 fatty acid docosahexaenoate reduces cytokine-induced expression of proatherogenic and proinflammatory proteins in human endothelial cells. Arterioscler Thromb 1994;14:1829-36.

10. Morin C, Hiram R, Rousseau E, Blier PU, Fortin S. Docosapentaenoic acid monoacylglyceride reduces inflammation and vascular remodeling in experimental pulmonary hypertension. Am J Physiol Heart Circ Physiol 2014;307:H574-86.

11. Morin C, Blier PU, Fortin S. MAG-EPA reduces severity of DSS-induced colitis in rats. Am J Physiol Gastrointest Liver Physiol 2016;310:G808-21.

12. Banno F, Doisaki S, Shimizu N, Fujimoto K. Lymphatic absorption of docosahexaenoic acid given as monoglyceride, diglyceride, triglyceride, and ethyl ester in rats. J Nutr Sci Vitaminol 2002;48:30-5.

13. Yan Y, Wang Z, Wang X, et al. Branched chain fatty acids positional distribution in human milk fat and common human food fats and uptake in human intestinal cells. J Funct Foods 2017;29:172-7.

14. Yan Y, Wang Z, Greenwald J, et al. BCFA suppresses LPS induced IL-8 mRNA expression in human intestinal epithelial cells. Prostaglandins Leukot Essent Fatty Acids 2017;116:27-31.

15. Bligh EG, Dyer WJ. A rapid method of total lipid extraction and purification. Can J Biochem Physiol. 1959;37:911-7. 
16. Luddy FE, Barford RA, Herb SF, Magidman P, Riemenschneider RW. Pancreatic lipase hydrolysis of triglycerides by a semimicro technique. J Am Oil Chem Soc 1964;41:693-.

17. Garcés R, Mancha M. One-step lipid extraction and fatty acid methyl esters preparation from fresh plant tissues. Anal Biochem 1993;211: 139-43.

18. Van Pelt CK, Brenna JT. Acetonitrile chemical ionization tandem mass spectrometry to locate double bonds in polyunsaturated fatty acid methyl esters. Anal Chem 1999;71:1981-9.

19. Lawrence P, Brenna JT. Acetonitrile covalent adduct chemical ionization mass spectrometry for double bond localization in non-methyleneinterrupted polyene fatty acid methyl esters. Anal Chem 2006;78:1312-7.

20. Hamosh M, Scow RO. Lingual lipase and its role in the digestion of dietary lipid. J Clin Invest 1973;52:88-95.

21. Hamosh M, Sivasubramanian K, Salzman-Mann C, Hamosh P. Fat digestion in the stomach of premature infants: I. Characteristics of lipase activity. J Pediatr. 1978;93:674-9.

22. Hamosh M, Scanlon JW, Ganot D, Likel M, Scanlon KB, Hamosh P. Fat digestion in the newborn: characterization of lipase in gastric aspirates of premature and term infants. J Clin Invest 1981;67:838.

23. Innis SM, Dyer RA, Lien EL. Formula containing randomized fats with palmitic acid (16:0) in the 2-position increases 16: 0 in the 2-position of plasma and chylomicron triglycerides in formula-fed piglets to levels approaching those of piglets fed sow's milk. J Nutr 1997;127:1362-70.
24. Small DM. The effects of glyceride structure on absorption and metabolism. Annu Rev Nutr 1991;11:413-34.

25. Kiechle FL, Zhang X. Apoptosis: biochemical aspects and clinical implications. Clin Chim Acta 2002;326:27-45.

26. Nishijima K, Shukunami K-i, Yoshinari H, et al. Interactions among pulmonary surfactant, vernix caseosa, and intestinal enterocytes: intraamniotic administration of fluorescently liposomes to pregnant rabbits. Am J Physiol Lung Cell Mol Physiol 2012;303:L208-14.

27. Fortin S Compositions comprising polyunsaturated fatty acid monoglycerides or derivatives thereof and uses thereof. Google Patents 2012, Patent number 8,222,295 B2.

28. Morin C, Fortin S, Cantin AM, Rousseau É. Docosahexaenoic acid derivative prevents inflammation and hyperreactivity in lung: implication of PKC-Potentiated inhibitory protein for heterotrimeric myosin light chain phosphatase of $17 \mathrm{kD}$ in asthma. Am J Respir Cell Mol Biol 2011;45:366-75.

29. Calder PC. Fatty acids and gene expression related to inflammation. In: Labadarious D, Pichard C, eds. Clinical Nutrition: Early Intervention. Karger Publishers: Basel, Switzerland, 2002:19-40.

30. Lawrence T. The nuclear factor NF- $\mathrm{KB}$ pathway in inflammation. Cold Spring Harb Perspect Biol 2009;1:a001651.

31. Chow JC, Young DW, Golenbock DT, Christ WJ, Gusovsky F. Toll-like receptor-4 mediates lipopolysaccharide-induced signal transduction. J Biol Chem 1999;274:10689-92. 